\title{
A deterministic/stochastic model to predict the variation in bulk modulus of chalk
}

\author{
F. COLLIN*, Ch. SCHROEDER $\uparrow$, V. DE GENNARO $\ddagger$ and A. BOLLE $\dagger$
}

\begin{abstract}
Ekofisk, located $200 \mathrm{~km}$ west of the Norwegian coast, is one of the main oilfields in the North Sea. Since the early 1980 s severe compaction of chalk reservoir layers has been observed as a consequence of reservoir depletion during oil production. Subsequently, this compaction has been amplified by assisted oil recovery using seawater flooding. The development of our understanding of the inherent mechanisms of this phenomenon has been the objective of extensive experimental investigations in the last two decades. Owing to the very high cost of cored material from the reservoir, experiments are usually performed on chalk samples from an outcrop in Belgium lying at the same stratigraphic level as the Ekofisk reservoir chalks. However, even at the laboratory sample scale, experimental variability of material response is observed. From a theoretical and numerical point of view, the determination of the mechanical properties of the material is of utmost importance for accurate modelling at both sample scale (laboratory tests) and reservoir scale. The aim of this paper is to introduce a stochastic approach within a deterministic constitutive model of chalk to enable the influence of material heterogeneity to be included in analyses for the range of observed mechanical responses. In modelling the random distribution of material parameters, the time-consuming Monte Carlo simulation method is replaced by a more efficient stochastic modelling technique. The results are given in the form of statistical parameters for the experimental laboratory test responses. The parameters of the distribution law (mean value, range of variation, spatial correlation structure) are fitted to reproduce the range of experimental responses observed at sample scale. Interest is focused on the variability of the chalk bulk modulus, as observed during isotropic compression tests. The proposed methodology provides a satisfactory explanation for the variability of response observed at the sample scale. The potential for extending the proposed approach to reservoir scale is briefly discussed.
\end{abstract}

KEYWORDS: chalk; numerical modelling and analysis
Situé à $200 \mathrm{~km}$ à l'ouest de la côte norvégienne, Ekofisk est l'un des principaux champs pétrolifères de la mer du Nord. Depuis le début des années 1980, d'importants tassements des craies réservoirs ont été observés suite à la déplétion du réservoir pendant l'exploitation. Par la suite, ce tassement a été amplifié par la récupération secondaire utilisant le balayage à l'eau de mer. Le développement de notre compréhension des mécanismes à la base de ce phénomène a fait l'objet d'une recherche expérimentale intensive au cours des deux dernières décennies. Vu le coût très élevé des échantillons prélevés par forage dans les réservoirs, les expérimentations sont habituellement réalisées sur des échantillons de craie provenant d'un affleurement en Belgique, appartenant au même niveau stratigraphique que les craies réservoirs d'Ekofisk. Toutefois, même à l'échelle de l'échantillon de laboratoire, on observe une variabilité expérimentale de la réponse du matériau. D'un point de vue théorique et numérique, la détermination des propriétés mécaniques est d'une importance capitale pour une modélisation précise tant à l'échelle de l'échantillon (tests au laboratoire) qu'à l'échelle du réservoir. L'objectif de ce papier est d'introduire une approche stochastique dans un modèle constitutif déterministe de la craie, pour permettre d'inclure l'influence de l'hétérogénéité matérielle dans l'analyse de la variabilité observée de la réponse mécanique. Pour modéliser la distribution aléatoire des paramètres matériels, l'approche de Monte Carlo très coûteuse en temps de calcul est remplacée par une méthode de modélisation stochastique plus efficace. Les résultats sont fournis sous la forme de paramètres statistiques des réponses expérimentales obtenues au laboratoire. Les paramètres de la loi de distribution (valeur moyenne, amplitude des variations, structure de corrélation spatiale) sont ajustés pour reproduire la gamme des réponses expérimentales observées à l'échelle de l'échantillon. L'attention est portée sur la variabilité du module de compressibilité volumique qui a été observée dans les essais de compression isotrope. La méthodologie proposée fournit une explication satisfaisante de la variabilité expérimentale observée à l'échelle de l'échantillon. L'extension à l'échelle du réservoir est discutée brièvement.

\section{INTRODUCTION}

Many oilfields in the North Sea are located in chalk, a soft rock composed of calcite grains (coccolithes, parts of skeletons of unicellular organisms) or pieces of skeleton. Ekofisk, located $200 \mathrm{~km}$ west of the Norwegian coast, is one of the

Manuscript received 19 May 2004; revised manuscript accepted 1 December 2004

Discussion on this paper closes on 1 September 2005, for further details see p. ii.

* Fonds National de la Recherche Scientifique, Belgium.

$\dagger$ University of Liège, Belgium.

\$ Ecole Nationale des Ponts et Chaussées - LCPC (Cermes-Institut Navier), France. main oilfields in the North Sea. Exploitation of the Ekofisk field began in the early 1970s, and compaction of reservoir layers, and related seafloor subsidence, has been observed since 1985. The rate of subsidence has increased substantially owing to more recent assisted oil recovery by seawater flooding. The total amount of seafloor settlement observed up to now is about $10 \mathrm{~m}$ (Nagel, 2001) with a current subsidence rate of nearly $0.4 \mathrm{~m}$ per year. Consequently, remediation plans to ensure offshore installation safety, with significant extra costs and revision of production strategy, were necessary.

From the above, it is clear that an understanding of chalk compaction due to water flooding is practically very important. Delage et al. (1996) suggested that this phenomenon 
was evidence of hydromechanical coupling in the chalk, a multiphase geomaterial partially saturated with water (wetting fluid) and oil (non-wetting fluid). The conceptual framework describing the mechanics of unsaturated soils was suggested as a suitable means of modelling, both qualitatively and quantitatively, the mechanical behaviour of chalk. The applicability of this approach was confirmed during the Pasachalk EC projects (Pasachalk1, 2001; Pasachalk2, 2003), which included experiments on chalk samples partially saturated with different proportions of oil and water. The influence of the saturating fluids is explained through the notion of suction, including capillary effects and various physicochemical chalk-water interactions. Compaction, due to seawater flooding as the oil is removed, is interpreted as a wetting-induced collapse under constant load similar to that observed in many unsaturated soils (De Gennaro et al., 2004). This approach, based on unsaturated soil mechanics, provides a useful means of developing constitutive modelling of chalk behaviour. The model proposed by Alonso et al. (1990) for unsaturated soils was adapted for modelling reservoir chalk (Collin et al., 2002) and implemented in the finite element code LAGAMINE (Charlier, 1987) in order to perform reservoir simulations.

Calibration of the model was achieved using available experimental results performed on chalk samples in the laboratory, but the question of how to extend the material properties from the sample scale (a few hundred cubic centimetres) to the reservoir scale (thousands of cubic metres) still needed to be addressed. Even at the sample scale, variability of material response is observed, especially during isotropic stress paths, and it might be expected that this variability would increase at the reservoir scale owing to other sources of heterogeneity (e.g. local geology, tectonics).

As the material response spectrum cannot be captured by a classical deterministic approach, the solution proposed herein is to couple finite element computations, using an elasto-plastic model, with a stochastic approach. The former allows the general features of the mechanical behaviour of chalk to be modelled; the latter allows the inclusion of the influence of material heterogeneity on the possible range of solutions. These developments are used for the modelling of isotropic compression tests performed on oil-saturated samples of chalk where there is evidence to show that parameter variability significantly influences mechanical behaviour. The main parameters influencing model response are identified, and a spatial variability of these parameters throughout the sample is considered. The variability law adopted considers the range of variation around the mean value, as well as the spatial structure of these variations expressed in terms of their correlation.

Instead of the time-consuming Monte Carlo simulation method, a more efficient stochastic modelling technique (Bolle, 1988, 2000) is used to model the random distribution of the material parameters. The results are given in the form of statistical parameters for the experimental responses. The parameters of the distribution law (mean value, range of variation, spatial correlation structure) are fitted to reproduce the range of experimental responses observed at plug scale.

\section{EXPERIMENTAL RESULTS}

Material used in the experiments is chalk extracted from the CBR quarry near Liège (Belgium) and known as Lixhe chalk. This chalk is widely used in experimental studies because it comes from the same stratigraphic level as the Ekofisk reservoir chalk formations (Upper Cretaceous period). The Lixhe chalk is a very pure chalk $\left(98 \cdot 5 \% \mathrm{CaCO}_{3}\right)$ with a very low silica content. The mean range of porosity is between $42 \%$ and $44 \%$, and its permeability is around $1 \mathrm{mD}$ (Schroeder, 2002).

During two European projects PASACHALK, the behaviour of the chalk was studied under different stress paths and saturation conditions using samples, approximately $50 \mathrm{~mm}$ high by $25 \mathrm{~mm}$ diameter, cored from blocks of chalk. The oil used for saturation was a non-polar immiscible organic liquid, Soltrol $170^{\circledR}$ (C12-C14 isoalkanes, Phillips Petroleum Co.). As chalk behaviour is rate sensitive (De Gennaro et al., 2003), all experiments were performed at the same applied stress rate of $10^{-3} \mathrm{MPa} / \mathrm{s}$. The variability of the chalk clearly influenced the behaviour of the chalk observed during the drained isotropic tests, and for this reason the present study focuses on chalk behaviour during this particular stress path.

Typically, the response of the chalk during an isotropic test can be divided into three phases (Fig. 1). The first phase is almost linear, and corresponds to an 'elastic' regime, where deformations are mainly reversible. Permanent (plastic) strains occur as the stress level increases, and this second phase, referred to as the pore collapse phase, is characterised by a significant decrease in the porosity (Monjoie et al., 1990; Risnes et al., 1994). During the third phase, at stresses higher than those shown in Fig. 1, contacts between the calcite grains increase, and plastic hardening is observed, typically at mean stress levels above $30 \mathrm{MPa}$.

The yield stress for each sample is obtained by the intersection of the elastic and plastic tangent lines, as shown in Fig. 1. The variation of yield stress as a function of porosity is shown in Fig. 2. There is no clear correlation between yield stress and porosity, and the determination coefficient is very low (around 1\%).

The experimental data show natural variability: for example, values of the yield stress vary within the range 19$23 \mathrm{MPa}$. Similarly, the mean elastic and strain-hardening moduli vary from sample to sample. The variation in sample

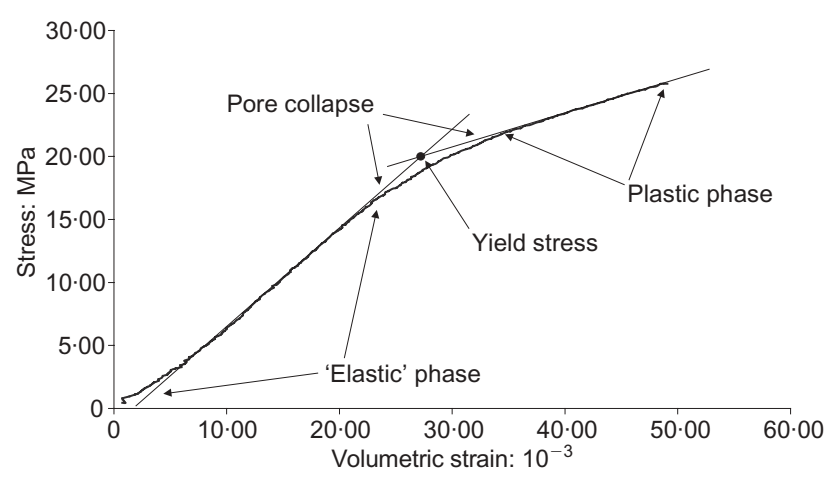

Fig. 1. Isotropic test on oil-saturated chalk

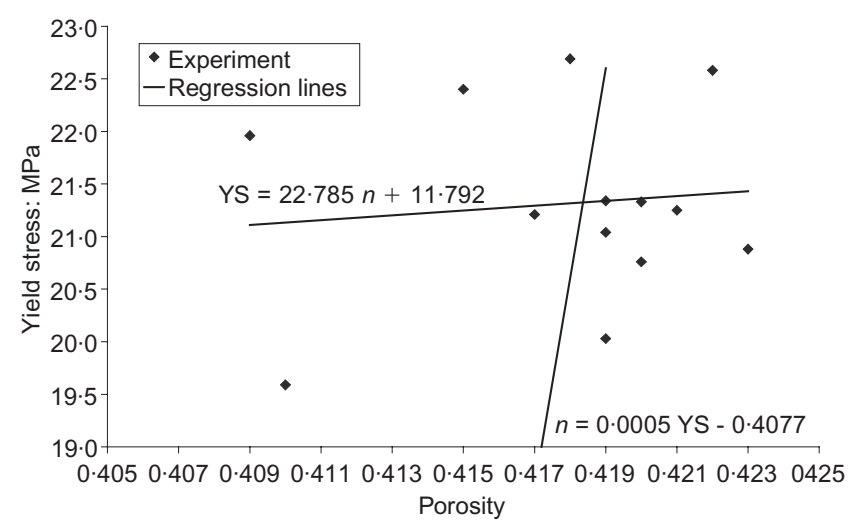

Fig. 2. Natural variability of initial yield stress 
behaviour can be characterised by examining the evolution of stiffness with stress or, more specifically, by evaluating a tangent modulus as a function of stress level. For the isotropic tests the appropriate parameter is the tangent (or incremental) bulk modulus $K$, which is defined as

$$
K\left(p^{\prime}\right)=\frac{\mathrm{d} p^{\prime}}{\mathrm{d} \varepsilon_{\mathrm{v}}}
$$

where $p^{\prime}$ is the mean effective stress and $\varepsilon_{\mathrm{v}}$ the volumetric deformation.

In practice, the computation of $K$, which is dependent on the slope of the curve between two experimental points, is highly influenced by the background noise of the measurement apparatus. The evaluation of the tangent modulus can be improved by using a smoothing technique, where the slope is computed not simply between two adjacent data points but between several points for which a regression line is determined. In all the following evaluations, 19 experimental points have been used for the smoothing technique.

The classical least squares method assumes that the 'independent' variable is error free. With both variables $\left(p^{\prime}\right.$ and $\varepsilon_{\mathrm{V}}$ ) containing measurement errors, the following relationship (Ricker, 1973) was preferred for defining the tangent modulus (as the slope of the regression line):

$$
K_{\mathrm{t}}=\frac{\mathrm{SD}\left(p^{\prime}\right)}{\mathrm{SD}\left(\varepsilon_{\mathrm{v}}\right)}
$$

where $\operatorname{SD}\left(p^{\prime}\right)$ and $\operatorname{SD}\left(\varepsilon_{\mathrm{V}}\right)$ are the standard deviations of the 19 values of mean effective stress and volumetric strain respectively.

Figure 3 shows the evolution of tangent bulk modulus for all 18 isotropic tests on the oil-saturated samples; a mean curve for all the results is also shown in the figure. Despite a scattering of the curves, it is possible to observe a common evolution of bulk moduli for all the samples. At low stress $\left(p^{\prime}<1 \mathrm{MPa}\right)$ bulk moduli are highly variable, and this is attributed to the relatively poor precision of the experimental measurements during the early stages of the test. With increasing values of stress the mean curve initially stabilises, around a $K_{\mathrm{t}}$ value of approximately $750 \mathrm{MPa}$, and then the value of the tangent modulus reduces. For the mean curve, the value of $K_{\mathrm{t}}$ gradually decreases as the mean stress increases above $15 \mathrm{MPa}$ (point A); this can be attributed to a progressive yielding of the chalk (collapse of the largest pores), and it continues up to a mean stress of $30 \mathrm{MPa}$ (point B). Above this value, the responses of all the chalk samples are more homogeneous, and a gradual increase in the tangent bulk modulus is observed. It is observed that the greatest variation in behaviour between the different samples occurs during the progressive collapse of the pore structure (i.e. between points $\mathrm{A}$ and $\mathrm{B}$ for the mean curve), and the

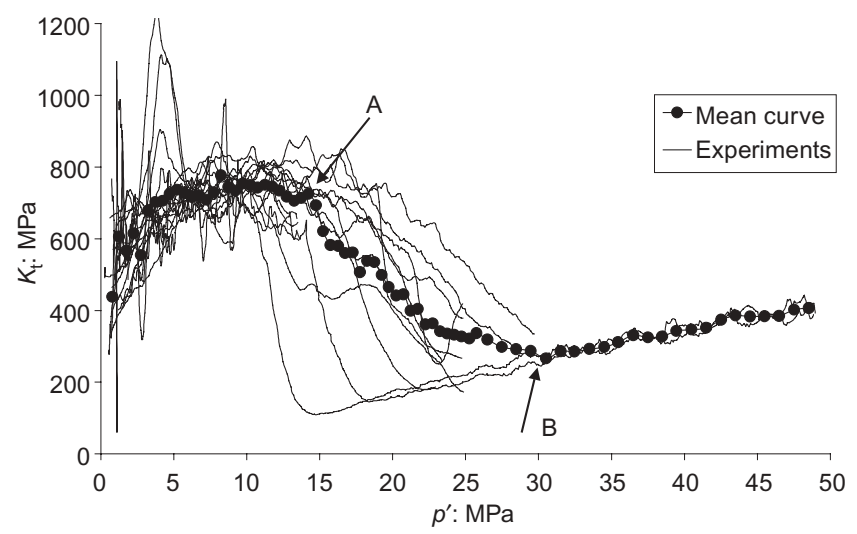

Fig. 3. Variation of bulk modulus with isotropic stress variation is influenced mainly by the yield stress - that is, the beginning of collapse and decrease in the value of $K_{\mathrm{t}}$. Although the average yield stress is $30 \mathrm{MPa}$ (point A), this varies for individual samples over the range 10-20 MPa. It is suggested that the variation in yield stress, and hence the subsequent collapse behaviour, is related to the pore size distribution within each sample, which may vary significantly from sample to sample even for samples where their average porosities are similar.

\section{MODELLING}

A suitable model is one that accounts for the behaviour, and the variability of behaviour, observed in the experiments. A simple 'deterministic' elasto-plastic model is able to predict only one loading curve, which may not even correspond to the average experimental behaviour. The model used in the present investigation introduces spatial variability in a way that couples the deterministic model with a stochastic model, and obtains solutions via the finite element method.

\section{Deterministic model}

The elasto-plastic model used is a modified version of the multi-mechanism constitutive law proposed by Collin et al. (2002). A simplified version of this model is sufficient to deal with saturated chalk, and the proposed Cap model is able to reproduce the different plastic mechanisms observed in chalk, namely pore collapse and frictional rupture (Shao \& Henry, 1991). The model is expressed in terms of the following stress invariants:

$$
\begin{aligned}
& I_{\sigma}=\sigma_{i i} \\
& I I_{\hat{\sigma}}=\sqrt{\frac{1}{2} \hat{\sigma}_{i j} \hat{\sigma}_{i j}} \quad \hat{\sigma}_{i j}=\sigma_{i j}-\frac{I_{\sigma}}{3} \delta_{i j}
\end{aligned}
$$

Following the additivity postulate, the strain rate is divided into an elastic component (superscript e) and a plastic one (superscript $\mathrm{p}$ ):

$$
\dot{\varepsilon}_{i j}=\dot{\varepsilon}_{i j}^{\mathrm{e}}+\dot{\varepsilon}_{i j}^{\mathrm{p}}
$$

Hooke's elasticity is assumed for the elastic part:

$$
\dot{\sigma}_{k l}=C_{k l i j}^{\mathrm{e}} \dot{\varepsilon}_{i j}^{\mathrm{e}}
$$

where $C^{\mathrm{e}}$ is the compliance elastic tensor. For the plastic part, a general framework of non-associated plasticity is adopted in order to limit dilatancy. In this case, the plastic flow rate is derived from a plastic potential $g_{\alpha}$ :

$$
\dot{\varepsilon}_{i j}^{\mathrm{p}}=\dot{\lambda}^{\mathrm{p}} \frac{\partial g_{\alpha}}{\partial \sigma_{i j}}
$$

where $\lambda^{\mathrm{p}}$ is a scalar multiplier and $g_{\alpha}$ is the plastic potential related to the plastic mechanism $\alpha$. Equations (5) and (6) can be rewritten as

$$
\dot{\sigma}_{k l}=C_{k l i j}^{\mathrm{e}}\left(\dot{\varepsilon}_{i j}-\dot{\lambda}^{\mathrm{p}} \frac{\partial g_{\alpha}}{\partial \sigma_{i j}}\right)
$$

Considering a general hardening/softening plastic law depending on the internal variable $\xi^{\alpha}$ (corresponding to the plastic mechanism $\alpha$ ), the consistency condition related to the yield function $f_{\alpha}$ can be formulated as

$$
\dot{f}_{\alpha}=\frac{\partial f_{\alpha}}{\partial \sigma_{i j}} \dot{\sigma}_{i j}+\frac{\partial f_{\alpha}}{\partial \xi^{\alpha}} \dot{\zeta}^{\alpha}=0
$$


Substituting equation (9) in equation (8), the expression of multiplier $\lambda^{\mathrm{p}}$ can be found and the stress rate can be computed:

$$
\dot{\sigma}_{k l}=\left(C_{k l i j}^{\mathrm{e}}-C_{k l i j}^{\mathrm{p}}\right) \dot{\varepsilon}_{i j}
$$

The proposed Cap model is a combination of a Cam clay model (to reproduce pore collapse), an internal friction law (to model frictional rupture), and a traction cut-off (Fig. 4):

Cam clay pore collapse model. The modified Cam clay yield surface is defined by the following expression:

$$
f_{1} \equiv I I_{\hat{\sigma}}^{2}+m^{2}\left(I_{\sigma}+\frac{3 c}{\tan \phi}\right)\left(I_{\sigma}-3 p_{0}\right)=0
$$

where $c$ is the cohesion, $\phi$ is the friction angle, $p_{0}$ is the preconsolidation pressure, which defines the size of the yield surface, and the coefficient $m$ is defined by

$$
m=\frac{2 \sin \phi}{\sqrt{3}(3-\sin \phi)}
$$

Assuming associated plastic flow, the preconsolidation pressure $p_{0}$ is related to the volumetric plastic strain $\mathrm{d} \varepsilon_{\mathrm{v}}^{\mathrm{p}}$ following the kinematic equation

$$
\mathrm{d} p_{0}=\frac{1+e}{\lambda-\kappa} p_{0} \mathrm{~d} \varepsilon_{\mathrm{v}}^{\mathrm{p}}
$$

where $\lambda$ is the compression coefficient and $\kappa$ is the elastic coefficient.

Equation (13) allows for both hardening and softening, according to the sign of the volumetric plastic strain, although in this study softening will not be considered.

Internal friction model. In order to model the frictional rupture, the Drucker-Prager failure cone is chosen and formulated as follows:

$$
f_{2} \equiv I I_{\hat{\sigma}}-m\left(I_{\sigma}+\frac{3 c}{\tan \phi}\right)=0
$$

A non-associated plasticity is also considered for the friction model, using a plastic potential definition similar to equation (14) where the dilatancy angle $\psi$ is used instead of the frictional angle $\phi$.

Traction cut-off. Traction stresses allowed by the DruckerPrager criterion depend on friction angle and cohesion. However, experiments have shown that this model leads to an overestimation of traction strength existing in chalk (Risnes et al., 1999). In order to avoid this drawback, another failure

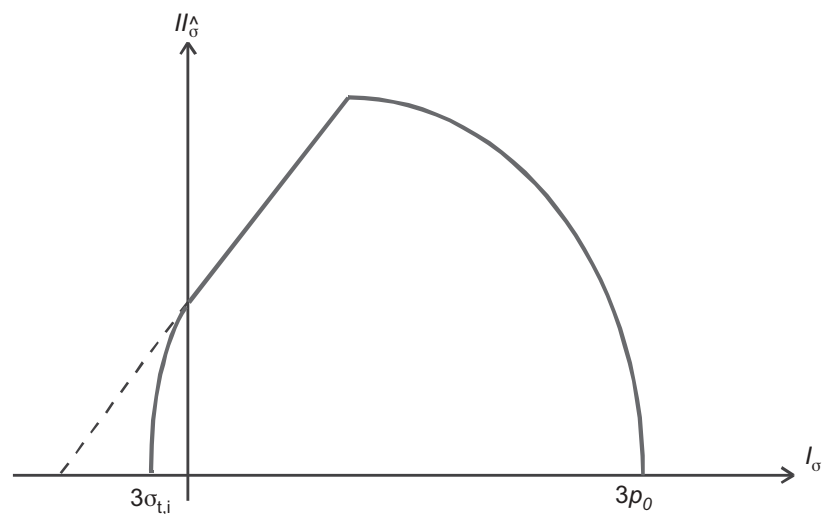

Fig. 4. Cap model for saturated chalk criterion has been introduced. A hyperbolic surface is used between the isotropic traction strength $\sigma_{t, i}$ and the stress point of the Drucker-Prager cone at nil mean stress. In the $\left(I_{\sigma}, I I_{\hat{\sigma}}\right)$ plane, that traction criterion is given by the following relationship:

$$
f_{3} \equiv I I_{\hat{\sigma}}^{2}-m^{2}\left(I_{\sigma}+3 \sigma_{t, i}\right)\left\{I_{\sigma}+\left[\frac{3 c(s)}{\tan \phi_{\mathrm{C}}}\right]^{2} / 3 \sigma_{t, i}\right\}=0
$$

Associated plasticity is chosen, and no hardening of the isotropic traction strength has been introduced in the model.

\section{Stochastic model}

A 100 isoparametric FE mesh $(20 \times 5)$ is used to model the sample during a monotonic, isotropic stress path. The stochastic model used to account for material variability is based on two assumptions: first, homogeneous random fields, limited to second-order statistical information (Vanmarcke et al., 1986), are assumed; and, second, the spatially variable parameter is the preconsolidation pressure $p_{0}$. The first assumption enables the property fluctuations to be fully described by an average value, a standard deviation and an autocorrelation model. The second assumption is based on the experimental results, which indicate that pore collapse begins at various stress levels (Fig. 3). The use of a random distribution for $p_{0}$, which controls pore collapse, is seen as an obvious way of representing the observed variable behaviour of the chalk.

The proposed stochastic approach is valid for a generally homogeneous body exhibiting some fluctuating properties. In the simulations, a purely random field of $p_{0}$ values is used to assign appropriate values of $p_{0}$ to each finite element; the fluctuations are described by a series of periodic functions. The frequency content of these functions is expressed as an autocorrelation model, $\rho(d)$, through the Wiener-Khintchine transform (Vanmarcke et al., 1986). Although different complex autocorrelation models exist (Bolle, 2000), a simple one (Fig. 5) is chosen as a first approach. This model defines a correlation decreasing linearly from 1 (for $d$ equal to 0 ) to 0 ( $d$ equal to $\left.d_{0}\right)$. The $d_{0}$ parameter is, more or less, related to the main wavelength of the fluctuation. This model is isotropic, because observations on chalk do not evidence preferential directions (Schroeder, 2002).

Random values of $p_{0, i}(i=1, N)$ are defined for each finite element, which respect the autocorrelation model; this is achieved by introducing random reduced variables, represented by $T_{i}$, which have a nil mean value and a unit variance:

$$
T_{i}=\frac{p_{0, i}-\hat{p}_{0, i}}{\mathrm{SD}_{p_{0, i}}}
$$

where $p_{0, i}$ is the $p_{0}$ value of the element $i, \hat{p}_{0, i}$ is the mean

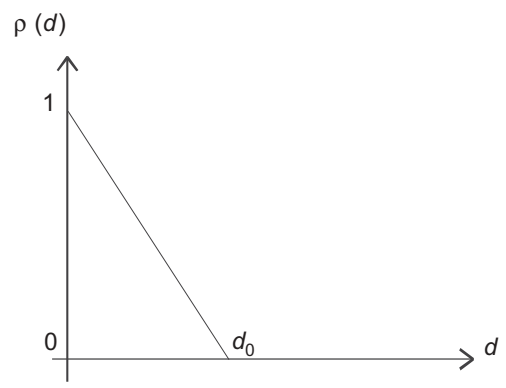

Fig. 5. Linear autocorrelation model 
value of the random field $p_{0, i}$, and $\mathrm{SD}_{p_{0, i}}$ is the standard deviation of the $p_{0, i}$ distribution.

The correlation matrix $\underline{R}$ is not modified by this operation, and:

$$
\underline{\underline{R}}\left(p_{0, i}\right)=\underline{\underline{R}}(\underline{T})=\left[\begin{array}{ccc}
1 & \cdots & \rho_{1, N} \\
\cdots & 1 & \cdots \\
\rho_{N, 1} & \cdots & 1
\end{array}\right]
$$

where $\rho_{i, j}$ is the autocorrelation value between finite element $i$ and $j\left(\rho_{i, j}=\rho_{j, i}\right)$.

A new set of independent (uncorrelated) random variables $Z_{i}$ are finally introduced as follows:

$$
\underline{Z}=\underline{A} \underline{T}
$$

where matrix $A$ is a rotation matrix.

Rosenblatt (1952) has shown that the rotation matrix is obtained by the transformation of the correlation matrix into a diagonal one. Each $Z_{i}$ variable has a probability distribution with a nil mean and a standard deviation equal to the square root of the associated eigenvalue of $\underline{R}(T)$. The transformation matrix is formed by the eigenvectors of the correlation matrix.

It is now possible to build up a random distribution of spatially correlated values of $p_{0, i}$, based on random independent $Z_{i}$. First it is necessary to build the correlation matrix $\underline{R}(T)=\underline{R}\left(p_{0}\right)$ and to compute its eigenvalues and eigenvectors. Then random values of the independent variables $Z_{i}$ $(i=1, N)$ are obtained by considering a normal distribution with a nil mean and a standard deviation equal to the square root of the associated eigenvalue. Considering equations (16) and (18) and knowing that $\underline{A}^{\mathrm{T}}=\underline{A}^{-1}$, spatially correlated $p_{0, i}$ hold:

$$
\underline{p_{0}}=\underline{p_{0}}+\underline{\mathrm{SD}} \mathrm{p}_{0} \underline{\underline{A}}^{\mathrm{T}} \underline{Z}
$$

\section{Statistical parameters of the model}

This coupled approach (deterministic + stochastic) can be used in finite element simulations of an isotropic test. With the 100-element FE mesh, the deterministic Cap model is used with a set of parameters corresponding to oil-saturated chalk (Table 1). The coupling with the stochastic model is introduced by assigning at each finite element spatially correlated $p_{0, i}$ values as described above. The model response depends on the initial values of spatially correlated $p_{0, i}$ and the parameters of the stochastic model $\left(\hat{p}_{0, i}, \mathrm{SD}_{p_{0, i}}\right.$ and $\left.d_{0}\right)$, which have to be chosen to reproduce the dispersion of the experimental results. The $d_{0}$ parameter introduces an internal length into the problem; different values have been tested (Fig. 6) in order to assess its influence on the moduli evolution (for $\hat{p}_{0, \mathrm{i}}=25 \mathrm{MPa}$ and $\mathrm{SD}_{p_{0, i}}=6 \mathrm{MPa}$ ).

For a value of $d_{0}$ smaller than the sample dimensions (namely $d_{0}=0.005 \mathrm{~m}$ ) all the $p_{0, i}$ are more or less independent (with a very low correlation), and a random drawing (Fig. 6) indicates a moduli evolution tending to the mean experimental curve based on data from all the tests. For a larger value of $d_{0}$ (namely $d_{0}=0.2 \mathrm{~m}$ ) the curve tends towards the behaviour for a single test where the transition between the elastic and plastic phase is steeper.

Each curve in Fig. 6 corresponds to a single set of $Z_{N}$

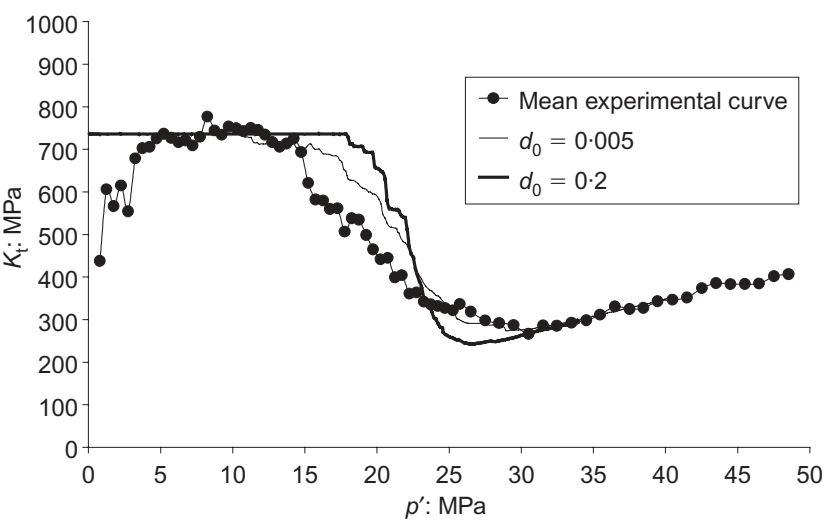

Fig. 6. Random isotropic response: influence of $d_{0}$

parameters. However, it is important to establish the average numerical response and its standard deviation in order to compare it with the set of experimental curves. Instead of the time-consuming Monte Carlo simulation method, a more efficient stochastic modelling technique (Bolle, 1988, 2000) is used to model the random distribution of material parameters. This method is inspired by the point estimate technique initially developed by Rosenblueth (1975).

Function $Y\left(p_{0, i}\right)$ is the response of the model in the $\left(\varepsilon_{\mathrm{v}}\right.$, $\left.p^{\prime}\right)$ plane, which can be characterised by its statistical information. The central value $Y_{\mathrm{C}}$ is given by the model response with the mean value of $p_{0, i}$ (undisturbed or deterministic response):

$$
Y_{\mathrm{C}}=Y\left(\underline{\hat{p}}_{0}\right)
$$

The other statistical parameters are obtained by introducing the random nature of $p_{0}$ into the model. Disturbed functions $Y_{i}^{+}$and $Y_{i}^{-}$are the model responses for special values of $Z_{i}$, defined as follows:

$$
\begin{aligned}
& Y_{i}^{+}=Y\left(\underline{\underline{p}}_{0}+\underline{\mathrm{SD}} p_{0} \underline{\underline{A}}^{\mathrm{T}}\left\{0, \ldots,+\sqrt{3 u_{i}}, \ldots, 0\right\}\right) \\
& Y_{i}^{-}=Y\left(\underline{\hat{p}_{0}}+\underline{\mathrm{SD}} p_{0} \stackrel{\underline{A}}{\mathrm{~T}}^{\mathrm{T}}\left\{0, \ldots,-\sqrt{3 u_{i}}, \ldots, 0\right\}\right)
\end{aligned}
$$

where $u_{i}$ is the eigenvalue corresponding to $Z_{i}$.

The proposed method allows the $Y$ distribution to be described based on the values of this function at three points: a central point $Y_{\mathrm{C}}$, and two disturbed points $Y_{i}^{+}, Y_{i}^{-}$. In Fig. 7 the distribution of the $Y$ functions is represented, and two other variables $d_{i}^{+}$and $d_{i}^{-}$are introduced as the difference between the disturbed function and the central point:

$$
\begin{aligned}
& d_{i}^{+}=Y_{i}^{+}-Y_{\mathrm{C}} \\
& d_{i}^{-}=Y_{i}^{-}-Y_{\mathrm{C}}
\end{aligned}
$$

Knowing that all the $Z_{i}$ variables are independent, the statistical parameters of $Y$ can be obtained by a summation of the disturbing effects of each $Z_{i}$ variable. Consequently, the average value and the standard deviation of the function are estimated by (Bolle, 1988, 2000)

$$
\widehat{Y} \cong Y_{\mathrm{C}}+\sum_{i=1}^{N} \frac{1}{6}\left(d_{i}^{+}+d_{i}^{-}\right)
$$

Table 1. Parameters of the Cap model for oil-saturated chalk

\begin{tabular}{l|c|l|c}
\hline Young's modulus: MPa & 1590 & Cohesion: MPa & 2 \\
\hline Poisson's ratio & $0 \cdot 14$ & Compressibility index & $0 \cdot 195$ \\
Friction angle: deg & 22 & Porosity & $0 \cdot 409$ \\
\hline
\end{tabular}




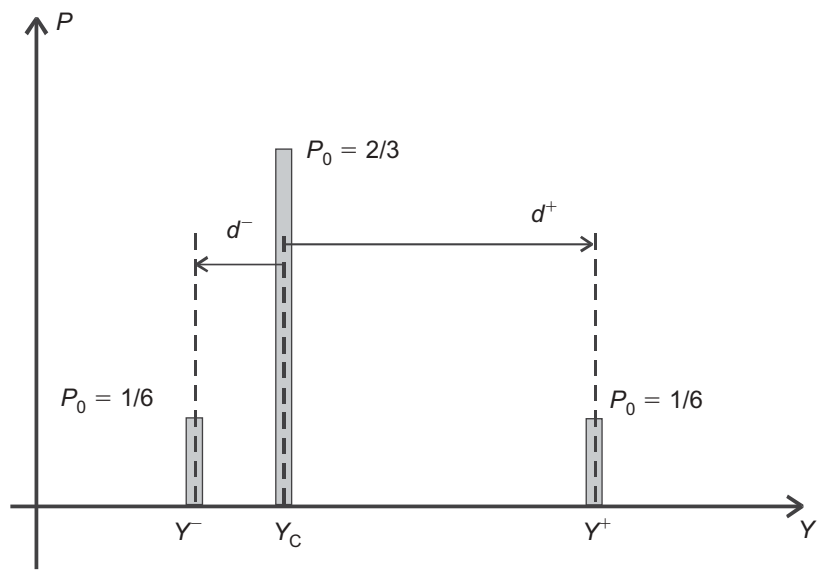

Fig. 7. Calculation of disturbing terms of $Y\left(p_{0}, i\right)$ due to variance of $Z_{i}$

$$
\mathrm{SD}^{2}(Y) \cong \sum_{i=1}^{N}\left[\frac{5}{36}\left(d_{i}^{+}+d_{i}^{-}\right)^{2}-\frac{d_{i}^{+} d_{i}^{-}}{3}\right]
$$

The skewness of the distribution can also be estimated. The three parameters $\hat{p}_{0, i}, \mathrm{SD}_{p_{0, i}}$ and $d_{0}$ were fitted to reproduce the range of experimental responses observed at the plug scale. From the experimental $\left(\varepsilon_{\mathrm{v}}, p^{\prime}\right)$ curves, the evolution curves for the bulk modulus are deduced using the smoothing technique described previously. Fig. 8 shows the mean experimental curve with vertical bars indicating the values of standard deviation, the mean numerical curve and two confidence limit curves for the numerical predictions corresponding to probabilities of $84 \%$ and $16 \%$ (with a gamma law distribution allowing for the skewness of the distribution). The parameters of the stochastic model are: $\hat{p}_{0, \mathrm{i}}=27 \mathrm{MPa}$, $\mathrm{SD}_{p_{0, i}}=12 \mathrm{MPa}$ and $d_{0}=0.015 \mathrm{~m}$.

Below a mean stress of $5 \mathrm{MPa}$ the agreement between the model and the experimental results is not so good, because the proposed methodology does not capture the observed increase of stiffness. Indeed, in this initial investigation, the model does not include any variation of elastic modulus. As pore collapse occurs (typically for mean pressures above $10 \mathrm{MPa}$ ) the observed decrease of the mean tangent bulk modulus is well predicted, as is the dispersion. The numerical curves, both mean $K_{\mathrm{t}}$ and confidence limit curves, exhibit an anomaly around a mean stress of $27 \mathrm{MPa}$. This is attributed to the sudden transition from an elastic to a plastic regime in the deterministic model. For the plastic phase following the pore collapse, the numerical and experimental moduli are increasingly consistent with a vanishing dispersion. Thus the proposed modelling provides a satisfactory

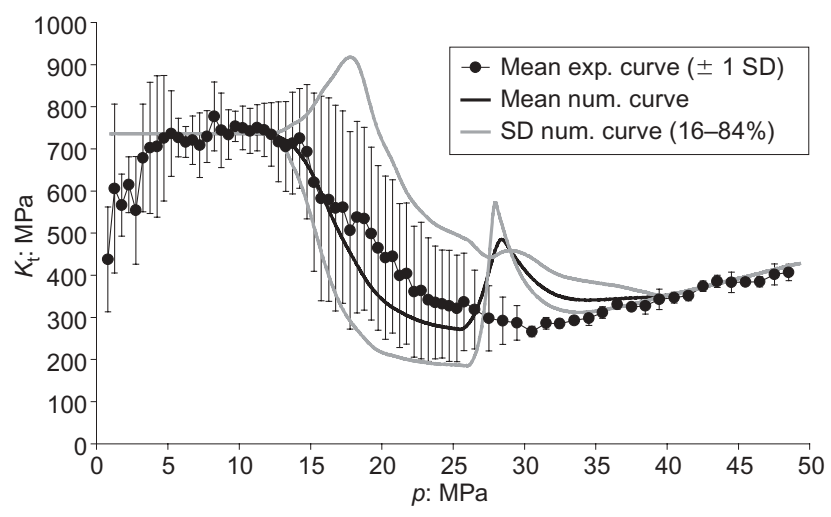

Fig. 8. Numerical response (mean curve and standard deviation) explanation for the variability of responses observed at the specimen scale in the laboratory.

\section{CONCLUSIONS AND FUTURE WORK}

Data from laboratory tests performed on specimens of chalk demonstrate a variability in material response during isotropic loading. The evolution of the tangent bulk modulus for a series of tests suggests that the initiation of pore collapse occurs at confining pressures ranging from 10 to $20 \mathrm{MPa}$, with no further significant volume changes occurring at pressures above $30 \mathrm{MPa}$. Within the pressure range $10-30 \mathrm{MPa}$ tangent bulk modulus variability is significant, whereas at pressures above $30 \mathrm{MPa}$ little or no variability in specimen behaviour is observed. At these higher pressures, the behaviour is typical of a strain-hardening material.

A model of chalk behaviour has been proposed that couples a deterministic elasto-plastic constitutive law with a stochastic approach. Material variability is described in terms of the preconsolidation pressure, $p_{0}$ : this is defined in terms of its mean value, its standard deviation and its spatial autocorrelation. This model has been used in finite element computations to reproduce isotropic compression tests on oil-saturated chalk samples using 100 elements. A modified point estimate technique is used to determine the numerical average curve and the numerical standard deviation. Comparisons between experimental and numerical results allow the influence of variability, as described by the stochastic parameters, to be assessed; it is shown that the proposed modelling strategy provides a satisfactory explanation for the variability observed in the experiments.

The investigation is limited to a single size of specimen, and an assessment of the methodology for samples of different size is still required. It is believed that the introduction of an internal length parameter $\left(d_{0}\right)$ for the variability of $p_{0}$ is an important factor in extending the assessment to chalk behaviour at reservoir scale. It is anticipated that results at a larger scale, using the same variability law, will exhibit a large reduction in variability, enabling valuable conclusions about the practical effects of material heterogeneity to be evaluated. However, other sources of parameter fluctuation are likely to be evident at the reservoir scale, owing to local geology and tectonics (discontinuities, fractures), and a specific treatment of these factors is required before the methodology can be extended to model behaviour at this larger scale.

\section{ACKNOWLEDGEMENTS}

The results presented in this note have been obtained within the framework of the European projects PASACHALK 1 (contract no. JOF3CT970033) and PASACHALK 2 (contract no. ENK6-2000-00089) carried out jointly by the University of Liège (Dpt. GeomaC, Belgium), the Ecole Nationale des Ponts et Chaussées (ENPC, Dpt. CERMES, Paris, France), and TotaFinaElf oil company (Drs Ph. Keul and A. Onaisi).

\author{
NOTATION \\ $\underline{\underline{A}}$ rotation matrix \\ $c$ cohesion \\ e void ratio \\ $f_{\alpha}, g_{\alpha}$ yield surface and plastic potential \\ $K$ bulk modulus \\ $p^{\prime}$ mean effective stress \\ $p_{0}$ preconsolidation pressure \\ $R$ correlation matrix \\ $\overline{T_{i}} \quad$ reduced random variables
}


$Y\left(p_{0, i}\right)$ response of the model in the $\left(\varepsilon_{\mathrm{v}}, p^{\prime}\right)$ plane

$Y_{\mathrm{C}}$ central value of function $Y\left(p_{0, i}\right)$ given by model response with mean value of $p_{0, I}$

$Y_{i}^{+}$and $Y_{i}^{-}$disturbed functions given by the model responses for special values of $Z_{i}$

$Z_{i}$ independent (uncorrelated) random variables

$\varepsilon_{\mathrm{v}}$ volumetric deformation

$\zeta^{\alpha}$ state variable corresponding to plastic mechanism $\alpha$

$\kappa$ elastic coefficient

$\lambda$ compressibility coefficient

$\lambda^{\mathrm{p}} \quad$ scalar plastic multiplier

$\sigma_{\mathrm{t}, \mathrm{i}} \quad$ isotropic traction strength

$\phi$ friction angle

$\psi$ dilatancy angle

\section{REFERENCES}

Alonso, E. E., Gens, A. \& Josa, A. (1990). A constitutive model for partially saturated soils. Géotechnique 40, No. 3, 405-430.

Bolle, A. (1988). Approche probabiliste en mécanique des sols avec prise en compte de la variabilité spatiale. $\mathrm{PhD}$ thesis, $\mathrm{EPF}$ Lausanne.

Bolle, A. (2000). Investigation and allowance for spatial variability. Rev. Fr. Géotech. 93, 55-66.

Charlier, R. (1987). Approche unifiée de quelques problèmes non linéaires de mécanique des milieux continus par la méthode des éléments finis. PhD thesis, University of Liège.

Collin, F., Cui, Y.-J., Schroeder, Ch. \& Charlier, R. (2002). Mechanical behaviour of Lixhe chalk partly saturated by oil and water: experiment and modelling. Int. J. Numer. Anal. Methods Geomech. 26, 897-924.

De Genarro, V., Delage, P., Cui, Y. C., Schroeder, Ch. \& Collin, F. (2003). Time-dependent behaviour of oil reservoir chalk: a multiphase approach. Soils Found. 43, No. 4, 131-148.

De Gennaro, V., Delage P., Priol, G., Collin, F. \& Cui, Y. C. (2004). On the collapse behaviour of oil reservoir chalk. Géotechnique 54, No. 6, 415-420.
Delage, P., Schroeder, Ch. \& Cui, Y.-J. (1996). Subsidence and capillary effects in chalk. Proc. Eurock 96, Turin, 1291-1298.

Monjoie, A., Schroeder, C., Prignon, P., Yernaux, C., da Silva, F. \& Debande, G. (1990). Establishment of constitutive laws of chalk and long term tests. Proc. 3rd Sea Chalk Symp., Copenhagen.

Nagel, N. (2001). Ekofisk geomechanics monitoring. Proceedings of the international workshop on geomechanics in reservoir simulation, Rueil-Malmaison.

Pasachalk1 (2001). Mechanical behaviour of partially and multiphase saturated chalks fluid-skeleton interaction: main factor of chalk oil reservoirs compaction and related subsidence, Part 1, Publishable Final report, European Joule III contract no. JOF3CT970033, Brussels.

Pasachalk2 (2003). Mechanical behaviour of partially and multiphase saturated chalks fluid-skeleton interaction: main factor of chalk oil reservoirs compaction and related subsidence, Part 2, Publishable Final report, Energy, Environment and Sustainable Development Programme, contract no. ENK6-2000-00089, Brussels.

Ricker, W. E. (1973). Linear regressions in fishery research. J. Fisheries Res. Board Canada 30, No. 3, 409-434.

Risnes, R., Gjesdal, S. A., Landaads, T. L. \& Madland, I. (1994). Changes in mechanical properties of chalk caused by deformation and by pressure. Proc. Eurock '94, Copenhagen, 853-860.

Risnes, R., Korsnes, R. I. \& Vatne, T. A. (1999). Tensional strength of chalks in direct and Brazilian tests. Proc. 9th Int. Cong. Rock Mech., Paris, 667-672.

Rosenblatt, M. (1952). Remarks on a multivariate transformation. Ann. Math. Stat. 13, 470-472.

Rosenblueth, E. (1975). Point estimates for probability moments. Proc. Nat. Acad. Sci. USA, 72, No. 10, 3812-3814.

Schroeder, Ch. (2002). Du coccolithe au réservoir pétrolier. $\mathrm{PhD}$ thesis, University of Liège.

Shao, J. F. \& Henry, J. P. (1991). Development of an elastoplastic model for porous rock. Int. J. Plasticity 7, 1-13.

Vanmarcke, E., Shinozuka, M., Nagakiri, S., Schueller, G. I. \& Grigoriu, M. (1986). Random fields and stochastic finite elements. Struct. Safety 3, 143-166. 